\title{
The role of marine silicate weathering in regulating marine carbon cycle over geological time scales
}

\author{
WEI-LI HONG ${ }^{1}$, MARTA E TORRES ${ }^{2}$ AND KUO-FANG \\ HUANG $^{3}$ \\ ${ }^{1}$ Department of Geological Sciences, Stockholm University \\ ${ }^{2}$ Oregon State University \\ ${ }^{3}$ Institute of Earth Sciences, Academia Sinica \\ Presenting Author: wei-li.hong@geo.su.se
}

Weathering of silicates coupled to carbonate formation (i.e. Urey reaction) has been shown as one of the most important processes regulating atmospheric $\mathrm{CO}_{2}$ through time:

reactive silicates $+\mathrm{H}_{2} \mathrm{O}+\mathrm{CO}_{2} \rightarrow$ clay + carbonate $+\mathrm{H}_{4} \mathrm{SiO}_{4}$ Eq.1

While terrestrial silicate weathering has been much studied and quantified, it is only recently that its marine counterpart has begun to receive attentions. Estimates of $\mathrm{CO}_{2}$ consumption rates through marine silicate weathering using lithogenic silicates $(0.3$ to $3.2 \mathrm{Tmol} \mathrm{C} /$ year, Jeandel and Oelkers, 2015; 1-4 Tmol C/yr, Torres et al., 2020) are comparable with the net $\mathrm{CO}_{2}$ consumption proposed for oceanic crust alteration (1.5-2.4 Tmol $\mathrm{C} / \mathrm{yr}$; Alt and Teagle, 1999). If we naively assume that all the silicic acid produced through $\mathrm{CO}_{2}$ consumption via Eq. 1 is released to the oceans, marine silicate weathering, including both oceanic crust and lithogenic silicates, could supply the oceans with as much $\mathrm{Si}$ as rivers do $(6.33 \mathrm{Tmol} \mathrm{Si} / \mathrm{yr}$; Sutton et al., 2018). In this study, we aim to examine the role of marine silicate weathering in the modern and past $\mathrm{Si}$ budgets by using the radiogenic strontium ratios $\left({ }^{87} \mathrm{Sr} /{ }^{86} \mathrm{Sr}\right)$ and stable strontium isotopic signatures $\left(\mathrm{d}^{88} \mathrm{Sr}\right)$ from locations where dissolution of lithogenic silicates and volcanic glass has been shown to drive authigenic carbonate precipitation. The ${ }^{87} \mathrm{Sr} /{ }^{86} \mathrm{Sr}$ ratios reflect decomposition of either the ${ }^{87} \mathrm{Sr}$-rich lithogenic silicates or the ${ }^{87} \mathrm{Sr}$-poor volcanic aluminosilicates, without complications associated with carbonate precipitation or microbial processes. In contrast, the $\delta^{88} \mathrm{Sr}$ signatures are fractionated during carbonate precipitation and thus provide a good constraint for the process. By simulating the pore fluid strontium \& silica concentrations, as well as ${ }^{87} \mathrm{Sr} /{ }^{86} \mathrm{Sr}$ and $\delta^{88} \mathrm{Sr}$ porewater profiles with a transportreaction model, we show that silicate alteration and the accompanying carbonate precipitation could be active in sediments that are millions of years old and as deep as a few hundred meters below seafloor. Our results emphasize the role of marine silicate weathering as a substantial $\mathrm{CO}_{2}$ sink over the long geological time scales. 